\title{
The Integration of Mainstream Psychotherapies in an Epistemological Framework
}

\author{
Zhizhong Kai \\ Factor-Inwentash Faculty of Social Work, University of Toronto, Toronto, Canada \\ Email: kaizhizhong@live.cn
}

How to cite this paper: Kai, Z. Z. (2021). The Integration of Mainstream Psychotherapies in an Epistemological Framework. Open Journal of Social Sciences, 9, 67-80. https://doi.org/10.4236/jss.2021.91005

Received: September 3, 2020

Accepted: January 8, 2021

Published: January 15, 2021

\begin{abstract}
Different forms of psychotherapy often construct theories and techniques based on different epistemological frameworks. Because of epistemological conflicts, some psychotherapy seems incompatible with each other. However, the problems encountered in psychotherapy are complex and multifaceted, and each psychotherapy has shown its shortcomings. So many researchers and practitioners were trying to use a combination of treatment techniques and integrate various psychotherapy in a treatment plan. Integrating different schools of psychotherapy requires an epistemological framework that can accommodate different psychotherapy to help them develop their strengths and prevent conflict. This paper proposed an epistemological framework based on system theory and the uncertainty principle. Through this framework, this paper attempted to reinterpret some of the mainstream psychotherapy and identified the underlying factors that are effective in their treatment. Finally, this paper put forward the methods and directions of integrating these psychotherapies into an epistemological framework.
\end{abstract}

\section{Keywords}

Epistemology, Psychotherapy, Integration, Key Elements, System

\section{Introduction}

Simon (2006) once proposed that psychotherapists are the core of psychotherapy, and the epistemology and world view of psychotherapists are the core of psychotherapy, which will directly lead to the corresponding therapeutic effect of psychotherapy. When faced with complex problems, a single treatment may be overstretched. A lot of psychotherapy is trying to integrate the techniques and 
ideas of other psychotherapies to improve the capacity to deal with complex and multi-faceted problems. This involves the question of what psychotherapies can be integrated and how to integrate. Some psychotherapies are derived from homologous philosophical theory, and they naturally blend well. The different schools of psychotherapy seem to be epistemologically incompatible, such as behavior therapy and psychoanalysis (Toska et al., 2010). Is it possible for them to merge?

By introducing the author's epistemology and reinterpreting the theory of mainstream psychotherapy, this paper will discuss the possibility and pathway of psychotherapy integration. The goal of this study is not just to bring together different schools of psychotherapy, but to identify the effective factors and provide a new epistemological framework to psychotherapy. To achieve this goal, I need to clarify the epistemological position of this paper in advance.

\section{Epistemological Position}

\subsection{Ontology}

Can truth be known? This is a question that needs to be answered in psychotherapy as well (Zerin, 1989). I believe that everything in the world is real, and there is only one reality and truth. But I believe human beings at this stage can't describe this reality and truth completely and perfectly. All knowledge is created by man to describe and reform the world. Originally, there is no knowledge in the world. Human beings create knowledge for themselves for survival and development. The rules of how the world works are not changed by the will of man or the creation of knowledge. All the knowledge and theories human-created only describe one part of the truth or describe the world correctly to some extent. Different people can construct their theories to understand the world. Human beings constantly create various artificial tools to measure the world. But the world has not changed by man's knowledge construction, and it has never been precisely measured by man. There is a widespread belief in psychotherapy that, "the truth is entrusted to and can be taught by a special group" (Zerin, 1989). But in my previous opinion, what can be taught is only the knowledge and opinion of the lecturer.

\subsection{World View}

My view of the world is mainly derived from two famous sayings in the Tao $\mathrm{Te}$ Ching: "Tao gave birth to the One; The One gave birth successively to two things, three things, up to ten thousand", and "The ways of Tao are followed by Self-so". The first sentence explains the origin and constitution of the world. This sentence depicts a scene that sounds a bit like the Big Bang theory, but not quite the same. In the view of Christians, God is one, who created Adam and Eve. Then they gave birth to their first child. Then their children continue to reproduce. To me, the One represents the most basic elements that make up the world. For example, in current physics, quarks, leptons, canonical bosons and 
Higgs particles are the smallest elements human can find. But is this the basic element? This is an unknown quantity. Human's present theory can only explain so far. There are different basic elements for different systems. For example, for society, the most basic element is the human, and for the human body system, the most basic element is the cell. The process from one to two, to three, and everything represents a process from quantitative to qualitative change. The moment when moving to "everything" is the significant moment when qualitative change is achieved, which means a new system is formed.

\subsection{System View}

When a system is formed, special functions and attributes that a single element did not have appear in the system. With the formation of the system, the operating rules of the system are formed immediately. "The ways of Tao are followed by Self-so" means that the world or each system has its own operating rules, and the only thing human can do is studying the rules and follow the rules. A large system can be composed of many small systems. The small system is subject to the laws of the large system, but also has its unique laws and special functions. The complexity of the system structure determines the number and level of advanced functions of the system. Under the framework of a large system, different small systems can interact with each other. This interaction will follow the rules of the larger system. At this point, each small system under the framework can be considered as a small element. The interaction between them may produce qualitative changes in these small systems. Different elements make up different structures that bring different functions to the system.

There are two states of the system: balance and unbalance. These two states are always in constant transition. Sometimes the transition is fast, and sometimes the transition cycle takes longer. The system is not always in a certain state. When the system is in one state, there is a tendency to go to another. But every time you go from state A to state B then back to state A, it might not just go back to the same state A, but to a new state A named state A'. So the system may spiral up or down until it collapses (such as death) or upgrades (such as an epiphany). This system view has something in common with structuralism and functionalism. The philosophical basis of structuralism is Machism, namely empir-criticism, which is mainly based on morphology, physiology and genetics, while the philosophical basis of functionalism is pragmatism and evolutionism.

\subsection{View of Human Essence}

A person is a large system made up of many different small systems. Anatomically, a person can have a digestive system, a nervous system, a respiratory system, a motor system, etc. From a psychological point of view, people have emotional systems, memory systems, cognitive systems, etc. At a microscopic level, an organ is made up of different cells which is a system. Each different system interacts with other different systems within the body. For example, people have a physical reaction (or even physical memory) when they are sad, and vice versa. 
At a macro level, a person can be seen as a combination of two systems: a physical system (the hardware system) and a belief system (the software system). A human's hardware system can be likened to computer hardware (CPU, memory, hard disk, etc.), while a human's software system can be likened to computer software (Photoshop, Microsoft Office, etc.). Human software does not refer to emotions, memory, cognition, etc. Because these are all attributes and functions of some part of certain body systems. For example, emotional circuits have been found in brain science and the memory system has been found in the body where neurons are concentrated, which could be the cerebral cortex, hippocampus, muscle, heart and so on.

The belief system is the operating logic and operating rules stored in the memory system. The human memory system is not just the cerebral cortex, the hippocampus and other parts of the brain, but a system composed of nerve cells that can be distributed in the heart, limbs and so on. That is the reason why after the transplant of the heart, there will be some recipients of the transplanted heart has a change of temperament. The belief system is like the operating system installed on a computer included the application software and a sea of files (such as video files, music files). Compared with Windows or macOS installed on the computer, the underlying operating system to human is the core belief, including people's values, world view and outlook on life (the meaning of life). The applications to a computer are the person's views of a particular field, such as the view of family, success, love, money, etc. Each file in the computer is the equivalent of a large or small event stored in the brain in the belief system. Some of the events are attached to the feeling of sadness, some of them adjust the belief system, and some of them may make mistakes that making it impossible to extract or read. A human's hardware system and software system cooperate and influence each other, which are unified to form a complete individual.

\subsection{The Essence of Society}

Each person is an independent system. Two persons staying together, even if they do not speak or touch each other, will unconsciously form a new system. This is embodied in the interpersonal bubble theory, which refers to people reserving a safe and comfortable interpersonal distance for themselves. The interpersonal distance and relationship are determined by the respective natures of the two independent systems and the natures of the physical system they are being, such as the distance between them and the orientation of each. So when two specific individuals appear in such a particular environment, the behavior or tendency they will exhibit is determined early on by the laws of their respective individual systems and the larger system (environment) they are in. The same is true when the number of people was increased to three, a three-persons system. When the number comes to hundreds of millions, this is society. The more complex the structure of the system and the number of elements of the system, the more abundant the functional attributes of the system will be. This explains the emergence of various social phenomena, such as conformity behavior, cul- 
tural phenomenon, class division and so on.

\section{Reinterpretation of Psychotherapy}

\subsection{New Understanding of Psychotherapy}

Based on the previous epistemological position, I believe that psychotherapy is an understanding of psychological problems based on their belief system and the treatment strategy after deduction based on their understanding. So every psychotherapy must have an epistemological framework behind it. The epistemological framework can determine the inclusiveness and compatibility of the psychotherapy. Inclusiveness reflects how close a theory is to the truth. The more inclusive it is, the more universal it is, the closer it is to the truth. The following examples have very good inclusiveness: Yang Zhenning's Yang-Baxter Equation, Newton's Second Law of Motion, and Einstein's Mass-Energy Equivalence. The best inclusive psychotherapy does not have the problem of cultural differences, so it does not have the problem of localization. Traditional psychotherapy was largely established under the European and American culture, theories, and norms of personhood, selfhood, and social norms (Caplan, 1998). Different from western culture, in Chinese traditional culture, instead of discussing psychology in isolation, we discuss it in a space on account of cognition, emotion and morality (Zhang, 2014). So, in my opinion, the localization of foreign psychotherapy is just patching up the theories of these foreign psychotherapies.

The compatibility problem is embodied in the epistemological collision between the client and the psychotherapist. Clients tend to be attracted to therapists who are close to their own cognitive belief systems consistent with (Arthur, 2000; Neimeyer \& Morton, 1997; Neimeyer et al., 1993). Many psychotherapists, on the other hand, just learn many treatment techniques of psychotherapy and never think of the epistemological level. Psychotherapist's uncertainty about his/her epistemology can affect the practice of psychotherapy (Zerin, 1989).

\subsection{Key Elements of Psychotherapy}

"It has been suggested that physical science metaphors of matter, force, and energy are no longer sufficient for describing neurological, psychological, behavioral, or social events (living processes) which can be understood only in terms of metaphors of information, pattern, form, and organization" (Keeney, 1982). When it comes to psychotherapy, in terms of the medical model, the goal of treatment is symptom-release (Toska et al., 2010). To me, somatization is a property of the human hardware system, as if the leaf is green because it has chlorophyll. All sorts of psychological symptoms (e.g., phobia) are like the system errors that pop up from time to time in the Windows system, which are manifestations of the software system. So, for symptoms to disappear, the first thing to do is to identify the source of the symptoms and the associated systems that the symptoms are associated with and the interactions between those systems. 
So, from the systematic perspective, there are some of the rules and key elements of how the world works related to psychotherapy: information, information carriers and interactions. First, there is no interaction between systems without information. Physics, for example, suggests that all forces can be reduced to four very basic forces: gravity, Electromagnetism, strong, weak (see Figure 1, Quigg, 2013).

These four forces can be understood as the relationship between the systems I have talked about. Each of the forces has corresponding "particles experiencing", which is equal to the exchange of information for each interaction. Information transmission also requires the information carrier (corresponding to the force carrier particle), which can be either a person or an objective object. So, in my epistemological framework, the world of psychotherapy looks like Figure 2.

In Figure 2, the outermost circle is information, which acts on a person's belief system through the information carrier. Each arrow is used to represent an interaction. Each person's growing life will be accompanied by different carriers and information, just like the eight planets around the sun, with the individual moving forward. In the process of interaction between individuals and carriers, a variety of events will constantly appear, thus forming memory nodes, shaping

Fundamental Force Particles
\begin{tabular}{|c|c|c|c|c|}
\hline Force & $\begin{array}{c}\text { Particles } \\
\text { Experiencing }\end{array}$ & $\begin{array}{c}\text { Force Carrier } \\
\text { Particle }\end{array}$ & Range & $\begin{array}{c}\text { Relative } \\
\text { Strength }\end{array}$ \\
\hline $\begin{array}{c}\text { Gravity } \\
\text { acts between } \\
\text { objects with mass }\end{array}$ & $\begin{array}{c}\text { all particles } \\
\text { with mass }\end{array}$ & $\begin{array}{c}\text { graviton } \\
\text { (not yet } \\
\text { observed) }\end{array}$ & infinity & $\begin{array}{c}\text { much } \\
\text { weaker }\end{array}$ \\
\cline { 1 - 4 } $\begin{array}{c}\text { Weak Force } \\
\text { governs } \\
\text { particle decay }\end{array}$ & $\begin{array}{c}\text { quarks and } \\
\text { leptons }\end{array}$ & $\begin{array}{c}W^{*}, W, Z^{0} \\
\left(W^{0} \text { and } Z\right)\end{array}$ & $\begin{array}{c}\text { short } \\
\text { range }\end{array}$ & \\
\hline $\begin{array}{c}\text { Electromagnetism } \\
\text { acts between } \\
\text { electrically charged } \\
\text { particles }\end{array}$ & $\begin{array}{c}\text { electrically } \\
\text { charged }\end{array}$ & $\begin{array}{c}\gamma \\
\text { (photon) }\end{array}$ & infinity & \\
\hline $\begin{array}{c}\text { Strong Force ** } \\
\text { binds quarks together }\end{array}$ & $\begin{array}{c}\text { quarks and } \\
\text { gluons }\end{array}$ & $\begin{array}{c}g \\
\text { (gluon) }\end{array}$ & $\begin{array}{c}\text { short } \\
\text { range }\end{array}$ & $\begin{array}{c}\text { much } \\
\text { stronger }\end{array}$ \\
\hline
\end{tabular}

Figure 1. Fundamental force particles (from https://brainly.in/question/3322014).

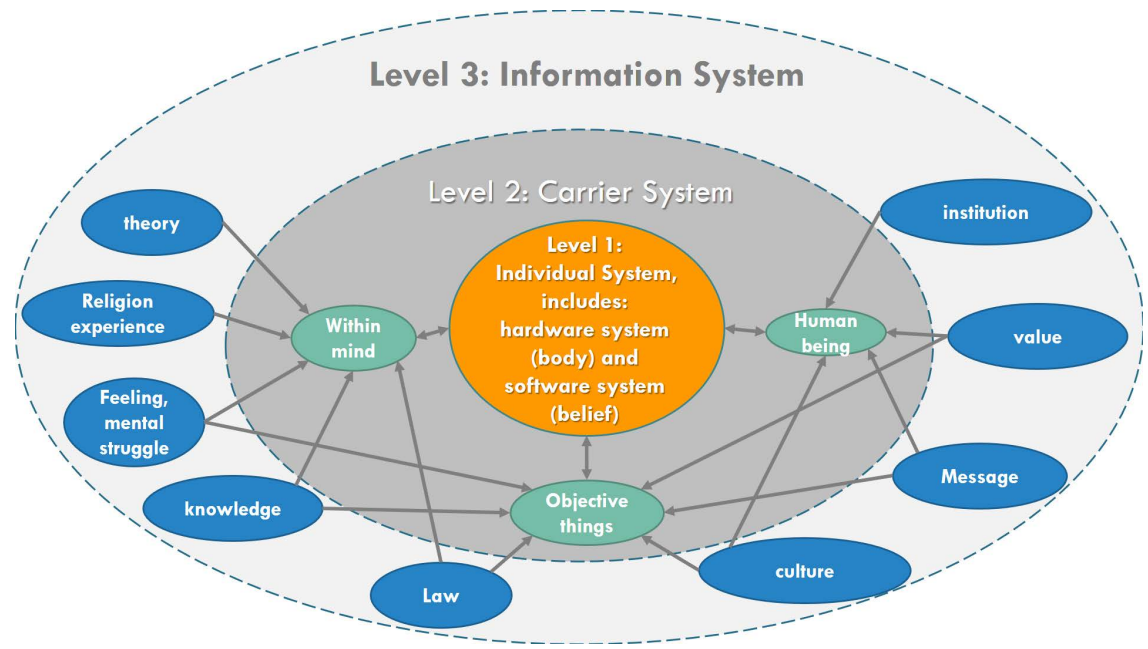

Figure 2. Information, carrier and interaction in psychotherapy. 
and changing our belief system. Events are nodes that qualitative change from a quantitative change in the process of interaction between systems. Once a qualitative change occurs, it must have an effect on the individual belief system. There is also an implicit dimension in this figure which is time. In other words, people's belief systems are constantly being modified by events and producing new information. Some information produced by people will exist permanently in the information system by embedded on some carrier, such as a book and people's mind. Even though the person's body is gone, there is a certain degree of immortality that can be achieved.

\subsection{Epistemology and Therapeutic Outcome}

As stated earlier, symptoms are simply a manifestation of the system's functions and properties. Therefore, some psychotherapists have stopped focusing on correcting or blocking the occurrence of symptoms and started to understand more about the reasons for the persistence of symptoms. The epistemology of these psychotherapists differs from that of the rationalist therapists. Studies have found that therapists with a stronger constructivist commitment are more effective when using constructivist therapy, such as Coherence Therapy (Toska et al., 2010). It seems that therapists who believe in a certain epistemology can achieve good outcomes by using relevant psychotherapy techniques within that epistemology framework. But isn't there a problem with the epistemological framework behind the methods used to evaluate outcomes? Several researchers have pointed out that evidence-based psychotherapy and randomized controlled trials are inherently problematic methods for validating efficacy, especially in extending laboratory conditions to real situations (Larner, 2004; Soldz \& McCullough, 2000). Such evidence-based psychotherapies and verification methods are both based on the epistemology of positivism and structuralism, and easily lead to focusing on treatment outcomes and ignoring the reasons why and how the treatment works.

Other researchers put their eyes on how to use meta-analysis to study what common factors are effective in psychotherapy, such as therapist's attitude, client's hope, therapeutic relationship, and found that common factors play an important role as therapeutic techniques (Duncan et al., 2010; Sprenkle \& Blow, 2004). So, people are beginning to pay more attention to the effects of relationships in dealing with many psychological issues (Carr, 2009). Even how the psychotherapy implement can affect the therapeutic effect (Finniss et al., 2010). Since the strict scientist-practitioner model, which seeks only evidence, is inherently problematic (Goodman \& Goodman, 2003), we should also try to use other methods of evaluating treatment effectiveness, like qualitative measures, discourse analysis, and practice-based research.

Symptoms are a state of imbalance in the system, and persistent symptoms are a state of new balance. A lot of times when a therapist tries to treat a stubborn symptom there may be a lot of resistance. That is because the client has entered a new state of balance and has no incentive to change. But if the client is still un- 
comfortable when it is in the new balance state, then there are pain points in the system. Then the therapist needs to start with the pain point to break the current balance, disturb the client's system, enter an unbalanced state, and finally lead the client to a new balanced state without pain.

It is not advisable to focus solely on the effectiveness of psychotherapy and ignore the process of treatment, the therapist's epistemology, the therapeutic relationship and other important factors that contribute to the outcome. The essence of these factors includes the interaction between systems, the adjustment of the belief system, the flow of information, and a new balance of the system.

\section{Psychotherapies in New Epistemology}

There are more than 100 kinds of psychotherapy in the world. Many psychotherapies share similar assumptions, theoretical backgrounds, and similar epistemological positions. I will just list some representative psychotherapies that in different epistemological positions and try to reconstruct them in my epistemological framework.

\subsection{Psychanalysis}

Traditional psychoanalysis holds that psychological problems stem from the conflict between the id and superego. Hence, the treatment process starts from helping the client deal with the sexual drive (Holmes, 1998; Green, 1995), develop to build a strong self (Stern, 1985). With the development of psychoanalysis, the focus of treatment has shifted to the early experiences of mother-infant (Klein et al., 1952; Bion, 1962), and object relation (Meltzer, 1975; Tustin, 1981; Sander, 1987; Hobson, 2002; Fonagy and Target, 2007).

Early psychoanalysis could not be confirmed by the scientific community because it was not supported by empirical research. Now more and more scientific experiments, especially brain science, have found the counterpart behind psychoanalysis. For example, in the classical theory of attachment, neuroscientists believe that the addictive disorder due to "the mesocorticolimbic dopaminergic reward circuit is activated in legislation situations" (Insel, 1997, 2003). Neuro mediators and brain activation regions were similar between maternal (Nitschke et al., 2004) and romantic love (Bartels and Zeki, 2000). Neural plasticity, the phenomenon of reconsolidation (Alberini et al., 2006), and the concept of "trace" (Ansermet and Magistretti, 2004) all support the arguments that environmental actions to the psychotherapy change the brain's neural circuitry (Ouss-Ryngaert \& Golse, 2010).

The results of these scientific experiments and research support the theory of psychoanalysis and support my theory as well. The corresponding material basis can be found for various psychological phenomena, even subconsciousness. The treatment techniques of psychoanalysis work on the client's endocrine system, memory system and nervous system. In the meantime, psychoanalysts connect the memory system and cognitive system by delivering and carrying the infor- 
mation between two systems. Then the clients will make meaning to this connection and reconstruct their belief system. Finally, if the client's hardware (endocrine system, nervous system) and software systems (belief system) are consolidated, the client's problems will be profoundly changed.

\subsection{Family Therapy}

Family therapy, like psychoanalysis, has many branches. Some compare the whole family to one person, and the symptoms of the family (e.g., fighting, family atmosphere, family breakdown) are likened to the symptoms of a person (e.g., anxiety, depression, schizophrenia). Some will start from the interaction within families to improve the communication mode and interaction mode. Some will also start from the family structure by drawing a family tree and find the changing strategy in the family tree.

However, when Chinese psychotherapists introduced these theories of western-originated family therapy into China, conflicts arose with the cultural values and social norms of the Chinese family (see $\mathrm{Zhu}, 2008$; $\mathrm{Xu}, 2008$; Yang et al. 2005). Because in the concept of family in China, the individual should give priority to the family and assume responsibility for the family (see Chang et al. 2005; Qian et al., 2002; Tseng, 1999 for example). The collectivism of the Chinese people conflicts with the individualism of the west. But is it irreconcilable?

In my epistemological framework, cultural conflicts can be interpreted and solved from a new perspective. Family therapy can be done at the individual level within the family, by changing the subsystem (the individual) to affect the larger system (the family). And vice versa, when a therapist tries to cure an individual, he can also start by changing the family to influence everyone in the family. The therapist can also start with the information that families communicate and the carriers of information to change family relationships, that is, to change the way in which the subsystems of a large system interact to achieve therapeutic goals. More specifically, for example, "family reconstruction", a technology in the Satir family therapy model, enables clients to learn new ways of interaction through role-playing (Zhang, 2014). This technique is about changing individual systems and information through behavioral experiences and then changing interactions between family members and then forming a new balance within the family system.

\subsection{Cognitive Behavioral Therapy}

Cognitive therapy has two epistemological orientations: rationalist and constructivist (See, Winter, 2008 for a recent review). The former mainly focuses on finding and changing clients' incorrect perceptions and beliefs, because they are the cause of various symptoms (Toska et al., 2010). The latter will take clients as "meaningful perturbances" (Toska et al., 2010). Therefore, the process of CBT is to start from the meaning of the client and help the client to rebuild a more feasible meaning, so that the client can obtain more flexible and effective coping 
strategies and functions (Toska et al., 2010). In this process, the cognitive perspective of psychotherapists will become an important factor to attract clients and psychotherapists to jointly construct meaning (Toska et al., 2010). Therefore, the psychotherapists of constructivist cognitive therapy are not problem-oriented and rarely give direct guidance. Instead, they explore and experience with clients (Granvold, 1996; Saferstein, 2006).

From the history of cognitive behavioral therapy, CBT combines the strengths of cognitive therapy and behavioral therapy. Not only that but then psychotherapists added meditation, mindfulness and other methods to cognitive behavioral therapy and created the ACT. Moreover, it has been reported that such integration can improve mood faster (Zhang, 2014). CBT integrates with other therapies in order to be able to provide a more comprehensive intervention to provide different systems (such as body system, motion system, belief system) for the client. Therapists in cognitive therapy also believe that cognitive changes can cause behavioral changes (Zhang, 2014). In my epistemological framework, the reason $\mathrm{CBT}$ integrated other psychotherapies and techniques is that the change in one subsystem can cause a change in other related subsystems. This is a far higher possibility of success than focusing on people's cognitive systems alone.

\subsection{Sandplay Therapy}

Sandplay therapy is based on projective techniques and Jungian psychology. The sandplay works allow a client to express inner information through the sandtray as a carrier. The therapist acts on the client through the carrier of sandtray by a specific method called "co-transference" (Bradway, 1991). With the sandtray and figures as the carrier, an intersubjective field of transference and countertransference can be established between the two systems of psychotherapist and client, and interaction can be generated (Orange, 1995). Therefore, the sandplay work is also believed to be co-created by the psychotherapist and the client (Maria et al., 2006).

The sandplay therapy, like other projective techniques, is the language of communication between the therapist and the client, which can also convey information and trigger a change in beliefs within the system of both parties. As Chodorow (1997, p. 179) notes, "Humans have always turned to the basic elements to express the imagination". Therefore, not only the sandtrey and figures, but all the symbols, patterns, cards, paper, pens, stones and other objective things can become the carriers helping to carry information and facilitate communication between systems.

\subsection{Family Constellation}

Family constellation emphasizes the role of system very much, taking phenomenology as the basis of its epistemology and the Zulu-constitution as the basis of its ontology (Cohen, 2006). "The knowledge of trans-generational loyalties is held not in the mind but from a deeper level of systemic, genetic, or cellular 
consciousness" (Gottesman and Hansen, 2005). In addition, in Zulu culture, the soul will continue to exist after the death of ancestors in the bodies of the offspring. As a result, they maintain some kind of contact with their ancestors (Lawson, 1985, pp. 24-25). This is the ancestral message being carried by the new carrier (the living Zulu).

Moreover, family constellation emphasizes the interplay of body and mind, which is a kind of somatic psychology. In the process of family constellation, the adjustment and structural change of the family system are carried out through the body feelings of the representatives. So, family constellation uses not only the information that comes from the body system, but it also uses that information to bring about changes in the internal relationships of the system.

Husserl's (1964) ideas of phenomenology provided me with excellent research method to analyze systems. Family constellation ascribes itself to phenomenology as well. But different from Husserl, Hellinger's, the founders of family constellation, study of phenomenology is more important for affecting his way of asking exploratory questions to the client's system. It is very helpful to help the representatives find real information in the system.

\section{Conclusion}

As can be seen from the basic theories of psychotherapy introduced above, they all focus on changing certain aspects of a client. From the views of system theory and the views of human essence, by changing one subsystem or changing the interaction between subsystems, they ultimately change the whole system. But their theories do not do a good job of explaining why they fail in some cases and other treatments succeed. With the development of psychotherapy, some psychotherapies began to learn from each other and moved toward integration.

Some scholars believe that in order to integrate different theories and techniques of psychotherapy, integration can only occur within a specific epistemological framework (Dickerson, 2010). "It then makes the argument that one can integrate theories within epistemologies and one can adopt practices and some theoretical concepts across theories and across epistemologies, but that it is impossible to integrate theories across epistemologies" (Dickerson, 2010). I think there is some compatibility between different epistemologies. From the above analysis and discussion, I used my epistemological framework to introduce and explain some basic principles of various psychotherapies. From this point of view, these psychotherapies can all live in peace under this framework. I have applied different techniques from various psychotherapy in my clinical practice but I have not found any incompatible between them. According to different clients, different treatment stages, and different problems, I chose a specific treatment technique to intervene the key elements (information, carrier, interaction, memory system, etc.). Based on this epistemological framework, I have invented a combination of techniques for psychotherapy, called psy-chess (Kai et al., 2020). Psy-chess combines theories and techniques of psychoanalysis, projective techniques, family constellation, story therapy, game theory, and painting 
therapy, which fully reflects my views on this paper. With the continuous development of epistemology, it is completely possible to find a more comprehensive and effective psychotherapy system that can integrate different psychotherapies for clients.

\section{Conflicts of Interest}

The author declares no conflicts of interest regarding the publication of this paper.

\section{References}

Alberini, C. M., Milekic, M. H., \& Tronel, S. (2006). Mechanisms of Memory Stabilization and De-Stabilization. Cell. Mol. Life Sci, 63, 999-1008. https://doi.org/10.1007/s00018-006-6025-7

Ansermet, F., \& Magistretti, P. (2004). A Chacun Son Cerveau Plasticité Neuronale et Inconscient. Paris: Odile Jacob.

Arthur, A. R. (2000). The Personality and Cognitive-Epistemological Traits of Cognitive Behavioral and Psychoanalytic Psychotherapists. British Journal of Medical Psychology, 73, 243-257. https://doi.org/10.1348/000711200160453

Bartels, A., \& Zeki, S. (2000). The Neural Basis of Romantic Love. Neuroreport, 11, 3829 3834. https://doi.org/10.1097/00001756-200011270-00046

Bion, W. R. (1962). Learning from Experience. London: Heinemann.

Bradway, K. (1991). Transference and Countertransference in Sandplay Therapy. Journal of Sandplay Therapy, 1, 25-42.

Caplan, E. (1998). Mind Game: American Culture and the Birth of Psychotherapy. Berkeley: University of California Press.

Carr, A. (2009). The Effectiveness of Family Therapy and Systemic Interventions for Child-Focused Problems. Journal of Family Therapy, 31, 3-45. https://doi.org/10.1111/j.1467-6427.2008.00451.x

Chang, D., Tong, H. Q., Shi, Q. J., \& Zeng, Q. F. (2005). Letting a Hundred Flowers Bloom: Counseling and Psychotherapy in the People's Republic of China. Journal of Mental Health Counseling, 27, 104-116.

https://doi.org/10.17744/mehc.27.2.hxfupdhht26b30a6

Chodorow, J. (1997). Jung on Active Imagination. Princeton: Princeton University Press.

Cohen, D. B. (2006). "Family Constellations": An Innovative Systemic Phenomenological Group Process from Germany. The Family Journal, 14, 226-233. https://doi.org/10.1177/1066480706287279

Dickerson, V. C. (2010). Positioning Oneself within an Epistemology: Refining Our Thinking about Integrative Approaches. Family Process, 49, 349-368. https://doi.org/10.1111/j.1545-5300.2010.01327.x

Duncan, B. L., Miller, S. D., Wampold, B. E., \& Hubble, M. A. (2010). The Heart and Soul of Change: Delivering What Works in Therapy. American Psychological Association. https://doi.org/10.1037/12075-000

Finniss, D. G., Kaptchuk, T. J., Miller, F., \& Benedetti, F. (2010). Biological, Clinical, and Ethical Advances of Placebo Effects. The Lancet, 375, 686-695. https://doi.org/10.1016/S0140-6736(09)61706-2

Fonagy, P., \& Target, M. (2007). The Rooting of the Mind in the Body: New Links be- 
tween Attachment Theory and Psychoanalytic Thought. J. Am. Psychoanal. Assoc, 55, 411-456. https://doi.org/10.1177/00030651070550020501

Goodman, K. S., \& Goodman, K. W. (2003). Ethics and Evidence-Based Medicine: Fallibility and Responsibility in Clinical Science. Cambridge University Press. https://doi.org/10.1017/CBO9780511545511

Gottesman, I. I., \& Hansen, D. R. (2005). Human Development: Biological and Genetic Processes. Annual Review of Psychology, 56, 263-288. https://doi.org/10.1146/annurev.psych.56.091103.070208

Granvold, D. K. (1996). Constructivist Psychotherapy. Families in Society: The Journal of Contemporary Human Services, 77, 345-359. https://doi.org/10.1606/1044-3894.932

Green, A. (1995). Has Sexuality Anything to Do with Psychoanalysis? Int. J. Psychoanal, $76,871-883$.

Hobson, P. (2002). The Cradle of Thought: Explorations of the Origins of Thinking. Oxford: Macmillan.

Holmes, J. (1998). The Changing Aims of Psychoanalytic Psychotherapy: An Integrative Perspective. Int. J. Psychoanal, 79, 227-240.

Husserl, E. (1964). The Idea of Phenomenology (G. Makhnikian, Trans.). The Hague, The Netherlands: Nijhoff. (Original Work Published 1913)

Insel, T. R. (1997). A Neurobiological Basis of Social Attachment. Am. J. Psychiat, 154, 726-735. https://doi.org/10.1176/ajp.154.6.726

Insel, T. R. (2003). Is Social Attachment an Addictive Disorder? Physiology \& Behavior, 79, 351-357. https://doi.org/10.1016/S0031-9384(03)00148-3

Kai, Z. Z., Ning, Y. J., \& Wu, F. F. (2020). Case Analysis for Psy-Chess: A Tool for Psychological Counseling and Organizational Counseling. Theory and Practice of Psychological Counseling, 2, 855-865. https://doi.org/10.35534/tppc.0212071

Keeney, B. P. (1982). What Is an Epistomology of Family Therapy? Family Process. https://doi.org/10.1111/j.1545-5300.1982.00153.x

Klein, M., Heimann, P., Issacs, S., \& Rivière, J. (1952). Developments in Psycho-Analysis. London: Hogarth Press.

Larner, G. (2004). Family Therapy and the Politics of Evidence. Journal of Family Therapy, 26, 17-39. https://doi.org/10.1111/j.1467-6427.2004.00265.x

Maria, E., Chiaia, \& Lauren, C. (2006). Correspondence. Journal of Analytical Psychology, 51, 301-306. https://doi.org/10.1111/j.0021-8774.2005.00589.x

Meltzer, D. (1975). Explorations in Autism: A Psycho-Analytical Study. StrathTay: Clunie Press.

Neimeyer, G. J., \& Morton, R. J. (1997). Personal Epistemologies and Preferences for Rationalist versus Constructivist Psychotherapies. Journal of Constructivist Psychology, 10, 109-123. https://doi.org/10.1080/10720539708404616

Neimeyer, G. J., Prichard, S., Lyddon, W. J., \& Sherrard, P. A. D. (1993). The Role of Epistemic Style in Counseling Preference and Orientation. Journal of Counseling and Development, 71, 515-523. https://doi.org/10.1002/j.1556-6676.1993.tb02234.x

Nitschke, J. B., Nelson, E. E., Rusch, B. D., Fox, A. S., Oakes, T. R., \& Davidson, R. J. (2004). Orbitofrontal Cortex Tracks Positive Mood in Mothers Viewing Pictures of Their Newborn Infants. Neuroimage, 21, 583-592. https://doi.org/10.1016/j.neuroimage.2003.10.005

Orange, D. M. (1995). Emotional Understanding: Studies in Psychoanalytic Epistemology. New York: Guilford Press. 
Ouss-Ryngaert, L., \& Golse, B. (2010). Linking Neuroscience and Psychoanalysis from a Developmental Perspective: Why and How? Journal of Physiology-Paris, 104, 303-308. https://doi.org/10.1016/j.jphysparis.2010.09.005

Qian, M. Y., Smith, C. W., Chen, Z. G., \& Xia, G. H. (2002). Psychotherapy in China: A Review of Its History and Contemporary Directions. International Journal of Mental Health, 30, 49-68. https://doi.org/10.1080/00207411.2001.11449532

Quigg, C. (2013). Gauge Theories of the Strong, Weak, and Electromagnetic Interactions. Princeton University Press. https://doi.org/10.1515/9781400848225

Saferstein, J. A. (2006). The Relationship between Therapists' Epistemology and Their Therapy Style, Working Alliance, and Use of Specific Interventions. Dissertation $A b$ stracts International, 68, 634B. (UMI No. 3249029).

Sander, L. W. (1987). Awareness of Inner Experience: A Systems Perspective on Self Regulatory Process in Early Development. Child Abuse Neglect, 2, 339-346. https://doi.org/10.1016/0145-2134(87)90007-X

Simon, G. M. (2006). The Hearth of the Matter: A Proposal for Placing the Self of the Therapist at the Center of Family Therapy Research and Training. Family Process, 45, 331-344. https://doi.org/10.1111/j.1545-5300.2006.00174.x

Soldz, S., \& McCullough, L. (2000). Reconciling Empirical Knowledge and Experience: The Art and Science of Psychotherapy. Washington DC: American Psychological Association. https://doi.org/10.1037/10567-000

Sprenkle, D. H., \& Blow, A. J. (2004). Common Factors and Our Sacred Models. Journal of Marital and Family Therapy, 30, 113-129.

https://doi.org/10.1111/j.1752-0606.2004.tb01228.x

Stern, D. N. (1985). The Interpersonal World of the Infant: A View from Psychoanalysis and Developmental Psychology. New York: Basic Books.

Toska, G. A., Neimeyer, G. J., Taylor, J. M., Kavas, A. B., \& Rice, K. G. (2010). Epistemology and Allegiance: Exploring the Role of Therapists' Epistemic Commitments on Psychotherapy Outcomes. European Journal of Psychotherapy \& Counselling, 12, 65-75. https://doi.org/10.1080/13642531003637783

Tseng, W. S. (1999). Culture and Psychotherapy: Review and Practical Guidelines. Transcultural Psychiatry, 36, 131-179. https://doi.org/10.1177/136346159903600201

Tustin, F. (1981). Autistic States in Children. London: Routledge \& Kegan Paul.

Winter, D. A. (2008). Cognitive Behaviour Therapy: From Rationalism to Constructivism? European Journal of Psychotherapy and Counselling, 10, 221-229.

https://doi.org/10.1080/13642530802337959

Xu, J. S. (2008). Tong Xin (Empathy). Beijing: Beijing Astronomy University Press.

Yang, G. S., Huang, G. G., \& Yang, Z. F. (2005). Huaren Bentu Xinlixue (Chinese Indigenous Psychology). Chongqing: Chongqing University Press.

Zerin, E. (1989). Epistemology and Psychotherapy. Transactional Analysis Journal, 19, 80-85. https://doi.org/10.1177/036215378901900204

Zhang, L. (2014). Bentuhua: Culturing Psychotherapy in Postsocialist China. Culture, Medicine, and Psychiatry, 38, 283-305. https://doi.org/10.1007/s11013-014-9366-y

Zhu, J. J. (2008). Laizi Dongfang de Xinli Zhiliaofa (The Psychotherapy from the Orient). Hefei: Anhui People's Publishing House. 